\title{
Worse Caries Experience Does Not Lead to Worse Overall Health
}

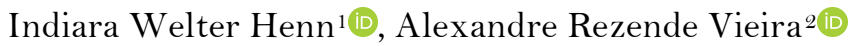

${ }^{1}$ Graduate Program in Dentistry, Pontifical Catholic University of Paraná, Curitiba, PR, Brazil

${ }^{2}$ Department of Oral Biology, School of Dental Medicine, University of Pittsburgh, Pittsburgh, USA.

Correspondence: Alexandre Rezende Vieira, University of Pittsburgh, 335 Sutherland Dr. Pittsburgh, PA, USA. 15261. E-mail: alexandre_vieira@pitt.edu

Academic Editor: Alessandro Leite Cavalcanti

Received: 22 February 2020 / Review: 03 July 2020 / Accepted: 17 August 2020

How to cite: Henn IW, Vieira AR. Worse caries experience does not lead to worse overall health. Pesqui Bras Odontopediatria Clín Integr. 2021; 21:e0028. https://doi.org/10.1590/pboci.2021.094

\begin{abstract}
Objective: To analyze caries experience depending on periodontitis affection concomitant or not with cardiovascular risks or mental health issues with the hypothesis that worse accumulated caries experience is not necessarily the result of the presence of concomitant overall health issues. Material and Methods: All subjects of this cross-sectional study were participants of the Dental Registry and DNA Repository project. Variables age, ethnicity, sex, caries experience, periodontitis and mental disease statuses and blood pressure assessment, dental clinical data (DMFT, DMFS and periodontitis) were evaluated and collected from the clinical records. We used chi-square, Fisher's exact, or Student's t-tests to determine differences in frequencies of sex, age, ethnicity, and dental clinical data depending on caries experience, periodontitis, mental health status, and cardiovascular risks. The established alpha was $5 \%$. Results: Of the total 1,437 subjects included in this study, 407 were individuals with high blood pressure and 1,030 were individuals without high blood pressure. Also, 558 were individuals with mental disease and 879 were individuals without mental disease. High blood pressure patients were mostly men $(47.17 \%)$ and women were the majority when analyzing patients with mental illness (60.04\%). Most of the patients in the different groups were white, with a mean age ranging from 15.4 to 88 years. Conclusion: We concluded that caries experience concomitant or not with periodontitis affection does not associate with high blood pressure and mental disease.
\end{abstract}

Keywords: Dental Caries; Periodontitis; Hypertension; Mental Disorders; Oral Health. 


\section{Introduction}

Periodontitis and dental caries are complex diseases with multiple and diverse exposures that impact upon risk of disease initiation (risk factors) or progression of existing disease (prognostic factors). Exposures include those that are inherited (e.g., genetic variants), those that are acquired, such as social, educational and economic factors, and the local environment (e.g., biofilm load or composition), other diseases (e.g., suboptimally controlled diabetes), and lifestyle (e.g., smoking, consumption of sugars, carbohydrate intake) factors [1]. These may arise in different combinations in different individuals and at an individual patient level may also have differentially weighted effects [1]. The outcome of both diseases, if left untreated, may be tooth loss, reduced masticatory function, poorer nutritional status, low self-esteem and quality of life, and negative general health impacts. There is also evidence of an association between tooth loss, dental caries, and periodontitis with higher all-cause mortality [2]. Great interest in oral health outcomes exists due to the argument that they can affect overall health [3].

Hypertension is widely studied for possible association with periodontitis [4]. The 3rd National Health and Nutrition Examination Survey (NHANES III) conducted a large study of almost 12,000 dentate adults to examine associations between periodontitis and blood pressure levels [4]. A positive linear relationship was found between systolic blood pressure and severe periodontitis in middle-aged individuals [5]. Also, the study of Han and Park [6] suggested that detection of high blood pressure may serve as a risk indicator for periodontal disease.

Mental health disorders are leading causes of morbidity, disability and mortality in the United States [7]. The World Economic Forum estimated that, by 2030, global costs of mental disorders are projected to reach US $\$ 6$ trillion; about two-thirds of these costs will be attributed to lost productivity related to disability [8].

In the literature, it is still not clear how dental caries and periodontitis present themselves concomitantly in the same individuals since most studies seldom look at both diseases together in populations. The European Organization for Caries Research and the European Federation of Periodontology (EFP/ORCA) suggest that dental caries and periodontitis also be analyzed in combination, individuals with both conditions versus individuals with none of the conditions [1]. Also, Djordjevic et al. showed that oral health is significant for general health and should not be separated from mental health because psychiatric patients have more caries and extracted teeth than individuals without mental illness. It is reasonable to expect that the prevalence of dental caries in hospitalized psychiatric patients should be higher than healthy individuals for several reasons: psychiatric disease leads to a weakening habits in oral hygiene, some antipsychotic drugs cause adverse effects in the oral cavity, such as dry mouth, the access of these patients to the dentist is, as a rule, limited, for several reasons [9].

Therefore, this study aimed to analyze caries experience depending on periodontitis affection concomitant or not with cardiovascular risks or mental health issues with the hypothesis that worse accumulated caries experience is not necessarily the result of the presence of concomitant overall health issues.

\section{Material and Methods}

Study Design and Sample

All subjects of this cross-sectional study were participants of the Dental Registry and DNA Repository project at the University of Pittsburgh School of Dental Medicine. This project was started in 
September 2006 and all the patients treated at the Dental Clinics of the University are invited to be part of the registry. All subjects provided written informed consent authorizing the extraction of dental and medical information from their records. These subjects are from the greater Pittsburgh area; for the most part, individuals with low socioeconomic status and hence high risk for all oral and overall health problems.

All 6,121 individuals in the registry recruited by October of 2018 were included in this study. A total of 1,437 patients were used for this study and variables age, ethnicity, sex, caries experience, periodontitis and mental disease statuses, and blood pressure assessment were obtained from medical records. Only those patients who had all of these data (caries experience, periodontitis, high blood pressure and history of mental health issue) completed in the DRDR report were added to the study. Patients who had incomplete data were excluded from this study.

\section{Data Collection}

Dental clinical data were collected from the clinical records of the study participants. Dental caries experience data were obtained through the DMFT (Decayed, Missing, Filled Teeth) and the DMFS (Decayed, Missing, Filled Surface) indexes [10]. DMFT was evaluated as a whole number, ranging from o to 32 teeth for how many teeth were decayed. DMFS was evaluated as the number of faces that were decayed, ranging from 0 faces to 160. Periodontitis was defined in individuals presenting at least three teeth exhibiting sites of clinical attachment loss equal or greater to $5 \mathrm{~mm}$ in two different quadrants, which corresponds to periodontitis stage III, Grade B in the latest classification [11]. The periodontitis data were dichotomized as to their presence or absence. All clinical conditions were evaluated by professionals in training under the supervision of experienced dentists. It was not possible to determine inter-rater variability statistics.

The definition of mental illness we used included any individual with depression, bipolar disorder, anxiety, schizophrenia, panic disorders, high stress, eating disorders, or, most often, the association of more than one psychic disorder. The diagnosis of high blood pressure was reported by the patient, who underwent treatment and follow-up with a specialized professional. For the covariates mental illness and high blood pressure, subjects' statuses were defined according to presence or absence of these conditions.

Statistical Analysis

Data were analyzed using the IBM SPSS software (version 22.0 for Windows, IBM Corp., Armonk, NY, USA). The Pearson's chi-square or Fisher's exact and Student's t tests were used to determine if there were differences in frequencies between both comparison groups by sex, age, ethnicity, and dental clinical data. The established alpha was $5 \%$.

Ethical Clearance

University of Pittsburgh Institutional Review Board - IRB (Approval \# 0606091).

\section{Results}

Of the 1,437 subjects included in this study, 28.32\% were individuals with high blood pressure and $71.68 \%$ were individuals without high blood pressure. Also, $38.83 \%$ were individuals with mental disease and $61.17 \%$ were individuals without mental disease. The highest frequencies found of mental illness were depression with $65.89 \%$ and anxiety $19.6 \%$, and these illnesses may be isolated or associated with more than 
one mental illness. The DMFT and DMFS values ranged from o to 32 and o to 151, respectively. High blood pressure patients were mostly men $(47.17 \%)$ and women were the majority when analyzing patients with mental illness (60.04\%). Most of the patients in the different groups were white, with a mean age ranging from 15.4 to 88 years. Other data like sex, age, geographic origin and dental clinical status were described on Table 1.

Table 1. Sample description.

\begin{tabular}{|c|c|c|c|c|c|c|}
\hline Variables & $\begin{array}{c}\text { High Blood } \\
\text { Pressure } \\
\text { N }(\%)\end{array}$ & $\begin{array}{c}\text { No High Blood } \\
\text { Pressure } \\
\mathrm{N}(\%)\end{array}$ & p-value & $\begin{array}{c}\text { Mental } \\
\text { Disease } \\
\mathrm{N}(\%)\end{array}$ & $\begin{array}{c}\text { No Mental } \\
\text { Disease } \\
\mathrm{N}(\%)\end{array}$ & p-value \\
\hline \multicolumn{7}{|l|}{ Sex } \\
\hline Women & $192(47.17)$ & $524(50.87)$ & 0.20 & $335(60.04)$ & $381(43.34)$ & $<0.001$ \\
\hline Men & $215(52.83)$ & $506(49.13)$ & & $223(39.96)$ & $498(56.66)$ & \\
\hline Age (Mean/SD) & $53.27 \pm 15.18$ & $44.83 \pm 15.76$ & 0.75 & $49.67 \pm 14.36$ & $45.64 \pm 16.85$ & 0.7814 \\
\hline \multicolumn{7}{|l|}{ Race } \\
\hline White & $303(74.45)$ & $792(76.89)$ & 0.055 & $447(80.11)$ & $648(73.72)$ & 0.001 \\
\hline Black & $97(23.83)$ & $202(19.61)$ & & $105(18.82)$ & $194(22.07)$ & \\
\hline Asian & $7(1.72)$ & $36(3.50)$ & & $6(1.07)$ & $37(4.21)$ & \\
\hline \multicolumn{7}{|l|}{ Caries } \\
\hline DMFT (Mean/SD) & $17.36 \pm 8.96$ & $18.14 \pm 7.99$ & 0.7771 & $18.48 \pm 8.27$ & $17.57 \pm 8.27$ & 0.7605 \\
\hline DMFS (Mean/SD) & $66.60 \pm 43.78$ & $66.44 \pm 40.59$ & 0.9861 & $69.40 \pm 41.31$ & $64.63 \pm 41.55$ & 0.7584 \\
\hline \multicolumn{7}{|l|}{ Periodontal Disease } \\
\hline Yes & $221(54.30)$ & $561(54.47)$ & 1.00 & $320(57.35)$ & $462(52.56)$ & 0.07 \\
\hline No & $186(45.70)$ & $469(45.53)$ & & $238(42.65)$ & $417(47.44)$ & \\
\hline Total & $407(28.32)$ & $1030(71.68)$ & & $558(38.83)$ & $879(61.17)$ & \\
\hline
\end{tabular}

SD: Standard Deviation.

Figures 1 and 2 show caries experience (DMFS and DMFT, respectively) based on having or not periodontitis. This increase in caries experience is independent of the presence or absence of high blood pressure or mental disease.

Also, we found similar values of prevalence of systemic diseases in patients with and without periodontitis. These results suggest a non-correlation between periodontitis and mental diseases or high blood pressure (Table 2).

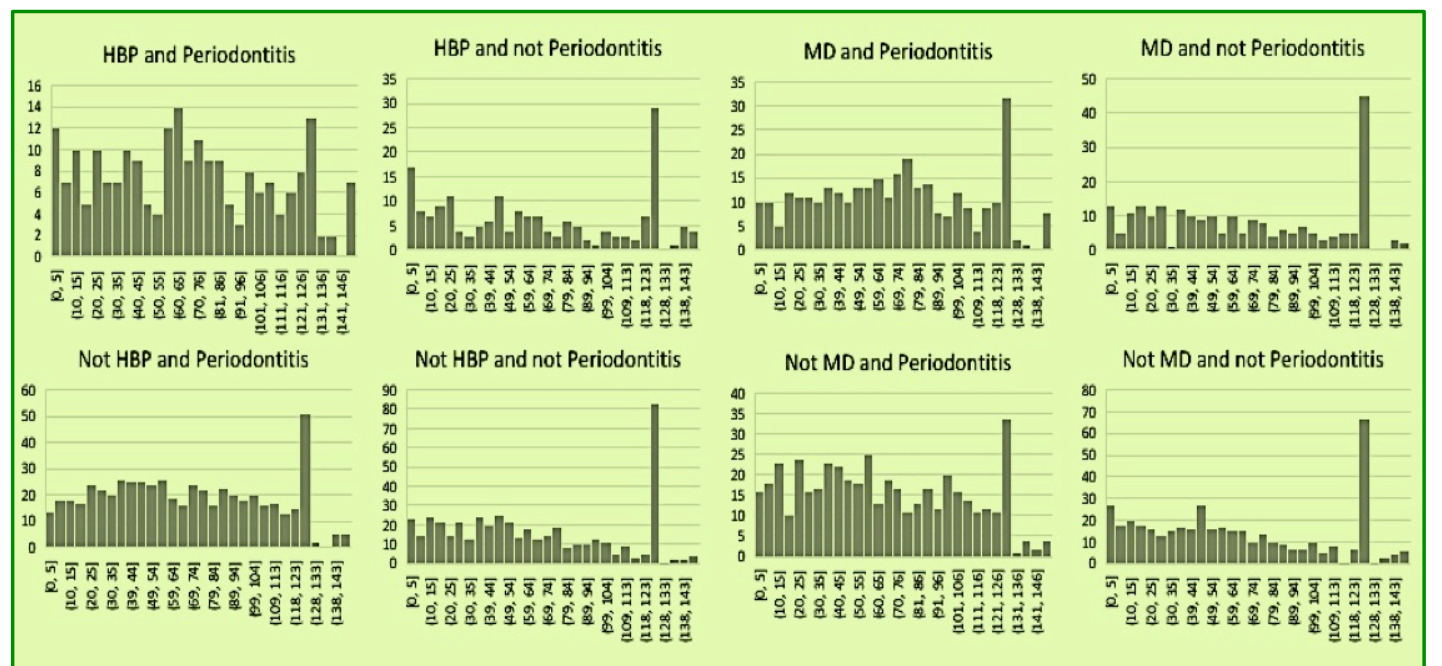

Figure 1. DMFS in individuals with High Blood Pressure (HBP) and Mental Disease (MD) and the presence and absence of Periodontitis. 


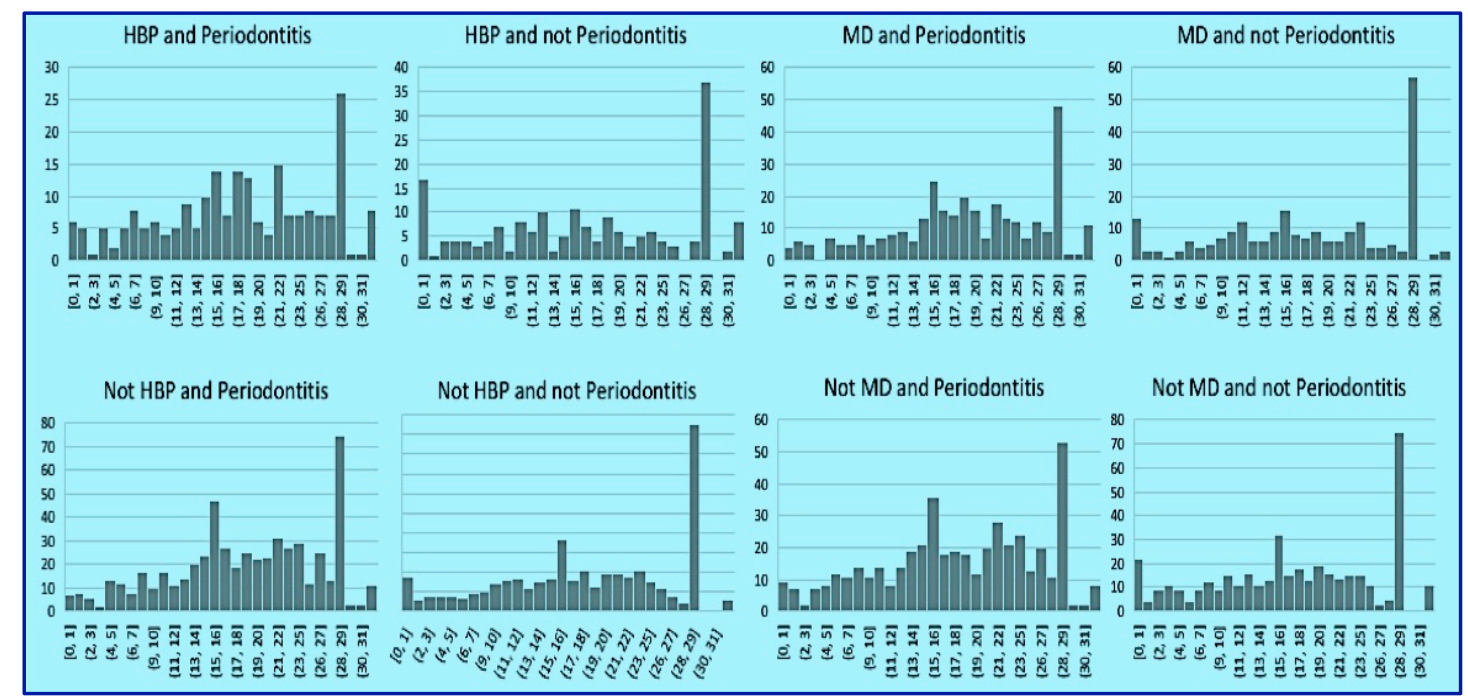

Figure 2. DMFT in individuals with High Blood Pressure (HBP) and Mental Disease (MD) and the presence or absence of Periodontitis.

Table 2. Prevalence of systemic disease in patients with periodontitis.

\begin{tabular}{cccccc}
\hline Periodontitis & $\begin{array}{c}\text { Mental } \\
\text { Disease }\end{array}$ & $\begin{array}{c}\text { High Blood } \\
\text { Pressure }\end{array}$ & $\begin{array}{c}\text { Mental Disease and } \\
\text { High Blood Pressure } \\
\mathrm{N}(\%)\end{array}$ & $\begin{array}{c}\text { Neither Systemic } \\
\text { Disease }\end{array}$ & Total \\
& $320(40.92)$ & $221(28.26)$ & $1 \%(\%)$ & $\mathrm{N}(\%)$ & $\mathrm{N}(\%)$ \\
\hline Presence & $320(14.58)$ & $127(16.24)$ & $782(54.4)$ \\
Absence & $238(36.33)$ & $186(28.40)$ & $74(11.30)$ & $157(23.97)$ & $655(45.6)$ \\
p-value & 0.2376 & 1.00 & 0.1068 & 0.0027 & \\
\hline
\end{tabular}

\section{Discussion}

According to our results, dental caries and periodontitis experience have no association with high blood pressure and mental disease. Our data contradicts the results of some studies that found a high risk of periodontitis in patients with high blood pressure $[5,6]$ and other studies that found an association of dental caries and periodontitis with mental disease $[9,12,13]$.

Regarding periodontal disease and hypertension, Paizan and Vilela-Martin [4] concluded that both diseases share multiple common risk factors (development of atherosclerotic cardiovascular complications, higher risk for cardiovascular events, namely, stroke, coronary heart disease), which should be controlled, so both diseases have their risks impacted. In patients with signs and symptoms of poor oral health, it is reasonable to recommend a medical evaluation (including blood pressure) and comprehensive periodontal examination, especially when unexplained increase C-reactive protein levels are identified because cardiovascular and periodontal diseases have several common risk factors, which may act on both diseases. Therefore, Paizan and Vilela-Martin [4] strongly believe that a simple periodontal evaluation should be a useful tool for assessing cardiovascular risk in general, especially in the hypertensive population. Dental caries and periodontitis are complex diseases and many factors (genetic variants, socio-economic factors, biofilm load or composition, smoking, carbohydrate intake) are involved in these processes and likely some overlap. Multiple exposures may contribute to their causal pathways; the correction of one risk factor may not lead to disease cure or even its prevention. It is important to state that increased risk does not necessarily imply causation, as certain factors may increase susceptibility to a disease developing but may not fulfill all the requirements required for a causal factor [1]. 
A higher experience of oral indexes in patients with mental illness was found in some studies $[9,12,13]$. Djordjevic et al. [9] showed in a study that comprised 190 hospitalized patients with schizophrenia and 190 mentally healthy patients that showed a value of DMFT index of $18.57 \pm 7.07$. So, hospitalized patients with schizophrenia had twice as many caries and extracted teeth and five times less filled teeth than the healthy people used as a comparison. The authors found an association of patient's age and the use of antiparkinsonics with highest values of DMFT in hospitalized patients with schizophrenia [10]. Also, Kisely [12], in a meta-analysis, found a high caries experience (DMFT index more than 20), a higher periodontitis experience (50 times more than healthy patients) and a probability of 2.7 times more of losing all their teeth in patients with severe mental illnesses (dementia and schizophrenia). Velasco-Ortega et al. [13] also showed that patients with schizophrenia had a decayed tooth score of $7.26 \pm 5.69$ compared with $6.5 \pm 4.37$ for patients in the control group, showing that patients with schizophrenia constitute a high-risk population for dental health.

The subjects we studied are from the greater Pittsburgh area; for the most part, individuals with low socioeconomic status and hence high risk for all oral and overall health problems tend to be over-represented in the patient pool [14]. However, according to Manji et al. [15], dental caries and periodontitis can be controlled by non-invasive and non-surgical interventions. Studies of populations with little or no access to such care shows that despite poor oral hygiene, most people keep most of their teeth for most of their lives. If only 10 to $15 \%$ of the population over 50 suffers from severe periodontal collapse, with the possibility that some of them may lose some teeth as a consequence. Also, Hugoson et al. [16] reported a study of a 30-year period that demonstrated the proportion of individuals with advanced periodontal destruction remained unchanged despite all efforts to scale and polish the dentition and have access to periodontal specialists.

We believe that the fact that this study was carried out based on an existing database is a limitation since we have no way of assessing how these data were collected, and we lost participants who did not have their data completely filled in the database.

\section{Conclusion}

The increase in caries experience, depending on periodontitis affection concomitant or not, is independent of the presence or absence of systemic diseases, like high blood pressure and mental disease.

\section{Authors' Contributions}

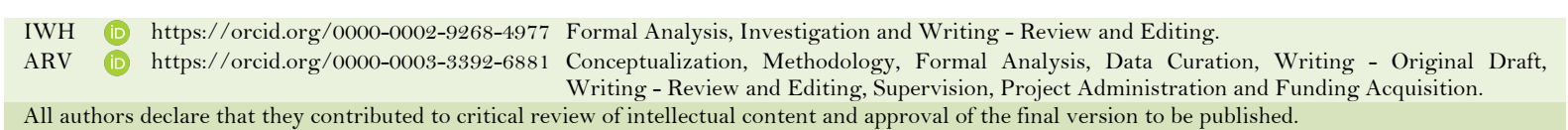

\section{Financial Support}

This work was supported by the Coordenação de Aperfeiçoamento de Pessoal de Nível Superior - Brasil (CAPES) - Finance Code 88881.131583/2016-01 to IWH.

\section{Conflict of Interest}

The authors declare no conflicts of interest.

\section{Data Availability}

Data for this work was obtained from the University of Pittsburgh School of Dental Medicine Dental Registry and DNA Repository project. 


\section{References}

[1] Chapple ILC, Bouchard P, Cagetti MG, Campus G, Carra MC, Cocco LN, et al. Interaction of lifestyle, behavior or systemic diseases with dental caries and periodontal disease: consensus report of group 2 of the joint EFP/ORCA workshop on the boundaries between caries and periodontal diseases. J Clin Periodontol 2017; 44(Suppl 18):39-51. https://doi.org/10.1111/jcpe.12685

[2] Kim JK, Baker LA, Davarian S, Crimmins E. Oral health problems and mortality. J Dental Sciences 2013; 8(2):115-20. https://doi.org/10.1016/j.jds.2012.12.011

[3] Barnett ML. The oral-systemic disease connection: An update for the practicing dentist. JADA 2006; 137(Suppl):5S6S. https://doi.org/10.1080/01944360608976719

[4] Paizan MLM, Vilela-Martin JF. Is there an association between periodontitis and hypertension? Curr Cardiol Rev 2014; 10(4):355-61. https://doi.org/10.2174/1573403x 10666140416094901

[5] Tsakos G, Sabbah W, Hingorani AD, Netuveli G, Donos N, Watt RG, et al. Is periodontal inflammation associated with raised blood pressure? Evidence from a National US survey. J Hypertens 2010; 28(12):2386-93. https://doi.org/10.1097/HJH.obo13e32833eofe1

[6] Han H, Park JB. Clinical implication of fasting glucose and systolic/diastolic blood pressure on the prevalence of periodontitis in non-diabetic and non-hypertensive adults using nationally representative data. Exp Ther Med 2018; 16(2):671-8. https://doi.org/10.3892/etm.2018.6260.

[7] Office of the Surgeon General. Center for Mental Health Services. National Institute of Mental Health. Mental health: A report of the Surgeon General. Pittsburgh, PA: US Department of Health and Human Services, US Public Health Service 1999.

[8] Dewa CS. The costs of mental disorders in the workplace: Can they be decreased? Sante Ment Que 2017; 42(2):31-8. https://doi.org/10.7202/1041912ar

[9] Djordjević V, Jovanović M, Miličć B, Stefanović V, Dejanović SD. Prevalence of dental caries in hospitalized patients with schizophrenia. Vojnosanit Pregl 2016; 73(12):1 102-8. https://doi.org/10.2298/VSP150917111D

[10] World Health Organization. Oral Health Surveys: Basic Methods. 4th ed. Geneva: WHO; 1997.

[11] Papapanou, PN, Sanz, M, Buduneli N, Dietrich T, Feres M, Fine DH, et al. Periodontitis: Consensus report of Workgroup 2 of the 2017 World Workshop on the Classification of Periodontal and Peri-Implant Diseases and Conditions. J Periodontol 2018; 89(Suppl 1): S173-S182. https://doi.org/10.1111/jcpe.12946

[12] Kisely S. No Mental Health without Oral Health. Can J Psychiatry 2016; 61(5):277-82. https://doi.org/10.1177/0706743716632523

[13] Velasco-Ortega E, Monsalve-Guil L, Ortiz-Garcia I, Jimenez-Guerra A, Lopez-Lopez J, Segura-Egea JJ. Dental caries status of patients with schizophrenia in Seville, Spain: a case-control study. BMC Res Notes 2017; 10:50. https://doi.org/10.1186/s13104-016-2368-9

[14] McGarvey EL, Leon-Verdin M, Killos LF, Guterbock T, Cohn WF. Health disparities between Appalachian and nonAppalachian counties in Virginia USA. J Community Health 2011; 36(3):348-56. https://doi.org/10.1007/s10900-010-9315-9

[15] Manji F, Dahlen G, Fejerskov O. Caries and periodontitis: contesting the conventional wisdom on the their aetiology. Caries Research 2018; 52(6):548-64. https://doi.org/10.1159/000488948

[16] Hugoson A, Sjödin B, Norderyd O. Trends over 30 years, 1973-2003, in the prevalence and severity of periodontal disease. J Clin Periodontol 2008; 35(5):405-14. https://doi.org/10.1111/j.1600-051X.2008.01225.x 